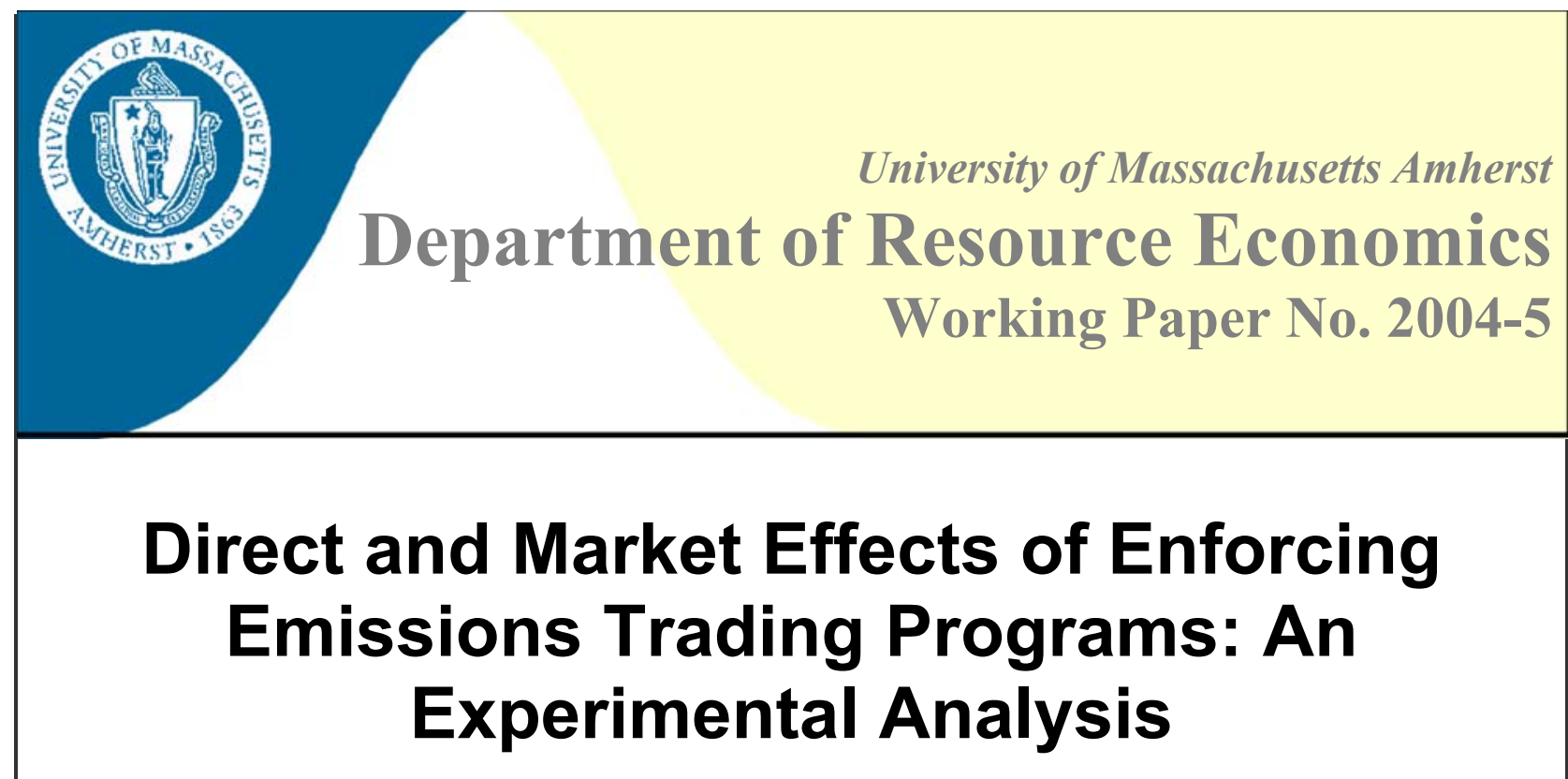

James J. Murphy ${ }^{1}$ and John K. Stranlund ${ }^{2}$

Abstract:

Since firms in an emissions trading program are linked together through a permit market, so too are their compliance choices. Thus, enforcement strategies for trading programs must account for not only the direct effects of enforcement on compliance and emissions decisions, but also the indirect effects that occur because changes in enforcement can induce changes in permit prices. This paper uses laboratory experiments to test for these direct and indirect market effects. Consistent with theoretical predictions, we find a direct effect of enforcement on individual violations, as well as a countervailing market effect through the permit price. Thus, the productivity of increased enforcement pressure to reduce noncompliance is partially offset by a countervailing price effect. Furthermore, there is no direct effect of enforcement on the emissions choices of firms, only a negative price effect. This suggests that the only way increased enforcement can have an impact on environmental quality is if it is large enough and applied widely enough to induce an increase in the equilibrium permit price.

Keywords: laboratory experiments, emissions trading, compliance, enforcement, permits JEL Classification: C91, L51, Q50

\footnotetext{
${ }^{1}$ James J. Murphy, Department of Resource Economics University of Massachusetts , 219A Stockbridge Hall, 80 Campus Center Way Amherst, MA 01003

E: stranlund@,resecon.umass.edu P: 413-545-5716 F: 413-545-5853

2 John K. Stranlund, Department of Resource Economics University of Massachusetts , 214 Stockbridge Hall, 80 Campus Center Way Amherst, MA 01003

E: stranlund@resecon.umass.edu P: 413-545-6328 F: 413-545-5853
} 
April 2004

\title{
Direct and Market Effects of Enforcing Emissions Trading Programs: An Experimental Analysis
}

\author{
JAMES J. MURPHY* \\ Department of Resource Economics \& \\ Center for Public Policy and Administration \\ University of Massachusetts-Amherst \\ JOHN K. STRANLUND \\ Department of Resource Economics \\ University of Massachusetts-Amherst \\ Prepared for the \\ Workshop on Experiments in Natural Resource Economics \\ Akureyri, Iceland \\ May 20-22, 2004
}

\begin{abstract}
Since firms in an emissions trading program are linked together through a permit market, so too are their compliance choices. Thus, enforcement strategies for trading programs must account for not only the direct effects of enforcement on compliance and emissions decisions, but also the indirect effects that occur because changes in enforcement can induce changes in permit prices. This paper uses laboratory experiments to test for these direct and indirect market effects. Consistent with theoretical predictions, we find a direct effect of enforcement on individual violations, as well as a countervailing market effect through the permit price. Thus, the productivity of increased enforcement pressure to reduce noncompliance is partially offset by a countervailing price effect. Furthermore, there is no direct effect of enforcement on the emissions choices of firms, only a negative price effect. This suggests that the only way increased enforcement can have an impact on environmental quality is if it is large enough and applied widely enough to induce an increase in the equilibrium permit price.

JEL Codes: C91, L51, Q50.

\section{Acknowledgements}

The research is funded by U.S. EPA - Science to Achieve Results (STAR) Program grant \#R829608 and by the Center for Public Policy and Administration, University of MassachusettsAmherst. Maria Alejandra Velez, Carrie Puglisi and Maria Claudia Lopez provided outstanding research assistance. Glenn Caffery programmed the software for this project. Wendy Varner provided valuable administrative support. The authors take full responsibility for any errors or omissions.
\end{abstract}

\footnotetext{
* Correspondence to James J. Murphy, Department of Resource Economics, Stockbridge Hall, University of Massachusetts-Amherst, Amherst, MA 01003, USA. Phone: (413)545-5716, Fax: (413)545-5853, E-mail: murphy@resecon.umass.edu.
} 


\section{Direct and Market Effects of Enforcing Emissions Trading Programs: An Experimental Analysis}

\section{Introduction}

By exploiting the power of a market to allocate pollution control responsibilities, well-designed emissions trading programs promise to achieve environmental quality goals more cheaply than traditional command-and-control regulations. It is clear, however, that the potential of emissions trading is jeopardized if these programs are not enforced well. In recognition of this fact, there is now a significant literature on compliance and enforcement of emissions trading programs [e.g., Keeler (1991), Malik (1990, 1992, 2002), vanEgteren and Weber (1996), Stranlund and Dhanda (1999), Stranlund and Chavez (2000)]. In general this literature suggests that compliance behavior in emissions trading programs is likely to be very different from behavior under command-and-control standards or fixed emissions taxes. One of the more important differences is that firms in an emissions trading program are linked together through the functioning of the permit market, while they operate largely independently under both command-and-control policies and emissions taxes. Thus, compliance and enforcement of emissions trading programs are inextricably linked to permit markets. Indeed, any factor that affects compliance decisions will in turn impact the permit market, which has its own indirect effect on compliance via the permit price. This suggests that any enforcement strategy or analysis of compliance decisions in emissions trading must account for the direct effects of factors that affect compliance, as well as their indirect market, or price, effects.

For this study we have designed and conducted laboratory experiments to examine the direct and indirect market effects of enforcement on pollution and compliance decisions. Our primary motivation in this work is the simple notion that having a theoretically sound and empirically validated understanding of compliance behavior in emissions trading programs is necessary for 
the proper design and evaluation of enforcement strategies for these programs. Although experimental techniques have been used to evaluate many other policy initiatives, including some aspects of emissions trading programs [e.g., Cason (1995), Cason and Plott (1996), Ishikida et al. (1998), Isaac and Holt (1999)], these techniques have not yet been widely applied to issues of regulatory enforcement or compliance behavior in emissions trading programs. ${ }^{1}$ The only other research that addresses compliance behavior in emissions trading programs is the recent work by Cason and Gangadharan (2004).

In this study we focus on imperfect compliance in emissions trading programs; hence, this study is not an analysis of some well-known programs that have been very successful in maintaining nearly perfect compliance. One of these, of course, is the $\mathrm{SO}_{2}$ Allowance Trading program. It is widely understood that the major contributors to the compliance success of this and other similar programs are the continuous emissions monitoring systems and sophisticated data transmission technologies that are required of all sources. Implementing emissions trading policies beyond their current applications implies moving them into contexts in which inducing and maintaining perfect compliance will be more difficult. These more difficult environments motivate our focus on imperfect compliance behavior.

Several of the hypotheses we derive from a straightforward model of compliance in emissions trading programs are supported by the experimental data. One of the most important of these is that there is a direct effect of enforcement on individual violations, as well as a countervailing market effect through the permit price. Increased enforcement-through increased monitoring or higher penalties — motivates firms to reduce their violations by purchasing more permits. This puts upward pressure on the equilibrium permit price, but higher permit prices

\footnotetext{
1 James Alm has successfully applied experimental techniques to the analysis of tax compliance. See, for example, Alm et al. (1992a, 1992b) and Alm (1998).
} 
motivate firms toward greater violations. Our experimental data are consistent with the theoretical prediction that the direct effect is always larger so that increased enforcement results in lower violations. However, the basic conclusion in this regard should be clear-the productivity of enforcement pressure in reducing noncompliance in emissions trading programs is partially offset by a countervailing price effect. Regulators that ignore this price effect would over-estimate the effectiveness of any attempt to reduce violations in an emissions trading program.

Another policy implication of this indirect price effect is that directing more enforcement pressure at a group of firms, presumably to motivate them toward greater compliance, is likely to involve a cost that regulators may not have recognized. The firms that are targeted with more enforcement pressure will purchase more permits to reduce their violations, thereby putting upward pressure on the equilibrium permit price. A higher permit price, however, motivates all the other firms in the program toward larger violations. Therefore, targeting groups of firms to increase their compliance may be accompanied by reduced compliance by other firms. This cannot happen under command-and-control regulation or a fixed emissions tax because firms under these regulations are not linked together through a permit market.

The experimental results are also consistent with a somewhat surprising result about enforcement and emissions choices - there is no direct effect of enforcement on the emissions choices of firms; there is only a negative price effect. ${ }^{2}$ That is, a firm's choice of emissions is independent of the enforcement strategy it faces, but this choice is not independent of the price of permits. Enhanced enforcement pressure can only induce a change in firms' emissions if it

2 Malik (1990) appears to be the first to have derived these conclusions in the case of emissions trading. Harford (1978) noted the result that the choice of emissions may be independent of enforcement in the case of an emissions tax. This result holds only if the monitoring probability that a firm faces is independent of its actual choice of emissions. 
causes an increase in the equilibrium permit price. Our experimental data provide strong support for this conclusion. One implication of this conclusion is that increased enforcement pressure applied to a single firm, or a small subset of firms, will have no environmental impact. The only way that increased enforcement can have an impact on environmental quality is if it is large enough and applied widely enough to lead to an increase in the equilibrium permit price.

Matters are quite different for emissions standards and taxes. Under fixed emissions standards, adjusting emissions levels is the only way a firm can change its level of noncompliance. Thus, increased enforcement of emissions standards will reduce emissions and improve environmental quality. In the case of a fixed emissions tax, however, increased enforcement will have absolutely no affect on emissions. In this case, as in the case of competitive emissions trading, firms' emissions choices are independent of changes in enforcement strategies. In contrast to emissions trading, however, the "price" of emissions is fixed so the indirect effect on emissions from enforcement cannot occur.

Although this work was motivated primarily by our desire to trace out the direct and market effects of enforcement, we did discover another effect that contradicts a standard theory of compliance behavior. Compliance choices by risk-neutral competitive firms in emissions trading programs should be independent of the initial allocation of permits. This is consistent with the well-known result that the emissions choices of perfectly competitive firms in emissions trading program are independent of initial allocations (Montgomery 1972). ${ }^{3}$ Our results contradict both of these conclusions. What appears to matter most here is how the initial allocation of permits determines who will be net sellers of permits and who will be net buyers. Our analysis suggests

\footnotetext{
${ }^{3}$ It is well known that Montgomery's independence result does not hold in the presence of market power [Hahn(1984)] or transaction costs [Stavins (1995)]. Similarly, compliance choices will not be independent of the initial allocation of permits in the presence of market power [van Egteren and Weber (1996), Malik (2002), Chavez and Stranlund (2003)], or transaction costs [Chavez and Stranlund (2004)].
} 
that net sellers tend to retain more permits, and have lower violations and higher emissions than the competitive equilibrium prediction, while net buyers hold fewer permits and tend toward higher violations and lower emissions. Since fewer permits change hands, permit prices tend to be higher than competitive equilibrium predictions.

The results of this paper make it clear that the compliance behavior of firms are linked together in emissions trading programs through the normal workings of permit markets. We provide a model of these linkages in the next section. In section 3 we provide details of the experiments we designed to test for these linkages. The results of the experiments are presented and discussed in section 4 . We conclude in section 5.

\section{Theory and Hypotheses}

The hypotheses of this paper are drawn from a model of compliance by a fixed number of risk neutral firms in a perfectly competitive emissions trading program. The abatement costs of firm $i$ are summarized by $c\left(q^{i}, \alpha^{i}\right)$, which is strictly decreasing and convex in the firm's emissions $q^{i}$. Heterogeneity of the firms is captured by the parameter $\alpha^{i}$, and we assume that total and marginal abatement costs are increasing in this parameter. A total of $Q$ emissions permits are distributed to the firms, free of charge. Firm $i$ receives $l_{0}^{i}$ permits initially, and holds $l^{i}$ permits after trading in a compliance period is complete. Assume competitive behavior in the permit market so that trade establishes a constant price per permit $p$.

If firm $i$ is noncompliant, its emissions exceed the number of permits it holds and the magnitude of its violation is $v^{i}=q^{i}-l^{i}>0$. If a firm is compliant, $q^{i}-l^{i} \leq 0$ and $v^{i}=0$. We do not allow firms to bank permits, so a firm's permit holdings will never exceed its emissions. To check for compliance, each firm is audited with probability $\pi$. A firm that is found to be in 
violation is assessed a penalty, $f\left(v^{i}, \phi\right)$. The penalty for a zero violation is zero but the marginal penalty for a zero violation is strictly positive $\left[f(0, \phi)=0\right.$ and $\left.f_{v}(0, \phi)>0\right]$. Furthermore, for a positive violation the penalty is increasing and strictly convex in the level of the violation $\left[f_{v}\left(v^{i}\right.\right.$, $\phi)>0$ and $\left.f_{v v}\left(v^{i}, \phi\right)>0\right]$. An increase in the parameter $\phi$ increases both total and marginal penalties; that is, $f_{\phi}\left(v^{i}, \phi\right)>0$ and $f_{v \phi}\left(v^{i}, \phi\right)>0$.

Assuming that each firm chooses positive emissions and permits and never over-complies, then $i$ 's problem is to choose emissions and permits to minimize $c\left(q^{i}, \alpha^{i}\right)+p\left(l^{i}-l_{0}^{i}\right)+\pi f\left(q^{i}-l^{i}\right.$, $\phi$ ), subject to $q^{i}-l^{i} \geq 0$. Let $<$ denote the Lagrange equation for this problem and let $\lambda$ be the multiplier attached to the constraint. The following first-order conditions are both necessary and sufficient to determine optimal choices of emissions and permit demand:

$$
\begin{aligned}
& \succ_{q}=c_{q}\left(q^{i}, \alpha^{i}\right)+\pi f_{v}\left(q^{i}-l^{i}, \phi\right)-\lambda=0 ; \\
& { }_{l}=p-\pi f_{v}\left(q^{i}-l^{i}, \phi\right)+\lambda=0 ; \\
& { }_{\lambda}=q^{i}-l^{i} \geq 0, \lambda \geq 0, \lambda\left(q^{i}-l^{i}\right)=0 .
\end{aligned}
$$

These conditions implicitly define a firm's optimal choices of emissions, permit demand, and violation as

$$
\begin{aligned}
& e_{i}=e^{i}\left(\pi, \phi, p, \alpha^{i}\right) ; \\
& l^{i}=l^{i}\left(\pi, \phi, p, \alpha^{i}\right) ; \\
& v^{i}=e^{i}-l^{i}=v^{i}\left(\pi, \phi, p, \alpha^{i}\right) .
\end{aligned}
$$

Note that these choices do not depend at all on a firm's initial allocation of permits, simply because this allocation does not enter any of the first-order conditions.

As we noted in the introduction, our focus is on enforcement and compliance in situations involving imperfect compliance. Assuming positive noncompliance $\left(v^{i}>0\right)$, the comparative 
statics of the firm's choices are contained in Table 1. Complete derivations of these results are available from the authors.

Holding the permit price constant, note how a firm responds to enhanced enforcement (either through increased monitoring or increased penalties). Combine [1] and [2] to obtain $-c_{q}\left(q^{i}, \alpha^{i}\right)=p$. This indicates the standard result that, under a competitive emissions trading program, firms will choose emissions so that their marginal abatement costs are equal to the prevailing permit price. Note, however, that this decision is independent of the enforcement variables. Thus, holding the permit price constant, increased enforcement does not lead to a change in firms' emissions $\left[q_{\pi}^{i}=q_{\phi}^{i}=0\right]$. Instead, they purchase more permits to reduce the extent of their violations $\left[v_{\pi}^{i}<0, v_{\phi}^{i}<0\right]$. As we will show in a short while, this will put upward pressure on the equilibrium permit price, which then has an indirect effect on the firms' choices. Note that a firm's emissions are decreasing in the permit price $\left[q_{p}^{i}<0\right]$, while its violations are increasing $\left[v_{p}^{i}>0\right]$. The intuition behind the latter result is that a higher permit price indicates a higher compliance price. ${ }^{4}$

Now let us turn to characterizing the equilibrium of an emissions permit market with noncompliant firms. Define the vectors $\alpha=\left(\alpha^{i}\right)_{i \in N}$, where $N$ is the set of regulated firms. Given that a total of $Q$ permits are issued to the firms, and the enforcement authority has committed itself to monitoring each firm with probability $\pi$ and imposing penalties with parameter $\phi$, the equilibrium permit price is $\bar{p}=\bar{p}(\pi, \phi, Q, \alpha)$. Using [4], the equilibrium permit price must equate aggregate demand for permits to aggregate supply; that is, $\bar{p}$ must satisfy

\footnotetext{
4 Stranlund and Dhanda (1999) argue that difference in firms' choices of violation in a competitive emissions trading program are independent of differences in their marginal abatement costs $\left[v_{\alpha}^{i}=0\right.$ in Table 1].
} 


$$
\sum l^{i}\left(\pi, \phi, \bar{p}, \alpha^{i}\right)=Q
$$

(Summations throughout are taken over the entire set of regulated firms).

In this study we are mainly interested in firm's choices of emissions and their violations. (Of course, a firm's permit holdings can be inferred directly from knowledge of its emissions and violation). Combine [4] and [5] to specify equilibrium emissions and violations:

$$
\begin{aligned}
& \bar{q}^{i}(\pi, \phi, Q, \alpha)=q^{i}\left(\pi, \phi, \bar{p}(\alpha, \pi, \phi, Q), \alpha^{i}\right) \\
& \bar{v}^{i}(\pi, \phi, Q, \alpha)=v^{i}\left(\pi, \phi, \bar{p}(\alpha, \pi, \phi, Q), \alpha^{i}\right) .
\end{aligned}
$$

To determine the direct and indirect price effects of enforcement on these equilibrium choices, obtain the following from [5]:

$$
\bar{p}_{\pi}=-\sum l_{\pi}^{i} / \sum l_{p}^{i}>0 \text { and } \bar{p}_{\phi}=-\sum l_{\phi}^{i} / \sum l_{p}^{i}>0 .
$$

The signs of $\bar{p}_{\pi}$ and $\bar{p}_{\phi}$ follow from $l_{\pi}^{i}>0$ and $l_{p}^{i}<0$ (see Table 1). Intuitively, increased monitoring or penalties motivates noncompliant firms to purchase more permits, which puts upward pressure on the equilibrium permit price. We, therefore, have our first hypothesis:

Hypothesis 1: Increased monitoring or penalties increases the price of emissions permits.

That increased enforcement puts upward pressure on permit prices has important implications for the effects of enforcement on individual choices of emissions and violations. From [6] obtain $\bar{q}_{\pi}^{i}=q_{\pi}^{i}+q_{p}^{i} \bar{p}_{\pi}=q_{p}^{i} \bar{p}_{\pi}<0$. Notice the potential for a direct effect of monitoring on emissions and an indirect effect through the permit price. However, the direct effect is zero 
because emissions choices are independent of enforcement strategies ( $q_{\pi}^{i}=0$ from Table 1$)$. Since increased monitoring puts upward pressure on the equilibrium permit price, firms respond to this by decreasing their emissions. The same conclusion follows if there is a change in the penalty for noncompliance.

Since aggregate emissions must fall with increased monitoring or penalties, given a fixed permit supply, aggregate violations must also fall. This would not be completely obvious by considering how individual equilibrium violations change with monitoring or penalties. From [6] obtain $\bar{v}_{\pi}^{i}=v_{\pi}^{i}+v_{p}^{i} \bar{p}_{\pi}<0$. The direct effect of monitoring is to reduce the violation of an individual firm $\left(v_{\pi}^{i}<0\right)$. However, increased monitoring increases the equilibrium permit price, which motivates the firm to increase its violation $\left(v_{p}^{i} \bar{p}_{\pi}>0\right)$. Since aggregate violations must fall with increased monitoring, each individual's violation must also fall. Thus, the direct effect of monitoring outweighs the indirect price effect. Increasing the penalty has the same qualitative effects as an increase in monitoring.

Our results about the equilibrium affects of enforcement on emissions and violation choices are summarized in the following hypotheses:

Hypothesis 2: The equilibrium effect of monitoring and penalties on individual violations is composed of a negative direct effect and a positive indirect market effect via the permit price. The direct effect is stronger than the price effect, so the total effect of increased monitoring or penalties is to reduce equilibrium violations.

Hypothesis 3: The direct effect of monitoring and penalties on emissions choices is zero. However, an increase in either monitoring or penalties will induce an increase in the equilibrium permit price, to which firms respond by reducing their emissions. 
We should also formalize the most obvious hypothesis of this model: the initial distribution of permits should have no impact on equilibrium outcomes.

Hypothesis 4: A redistribution of the initial allocation of permits has no effect on firms' choices of emissions and violations. Consequently, the equilibrium permit price is also independent of a redistribution of the initial allocation of permits.

\section{Experimental Design and Procedures}

\subsection{Experiment design}

The experiments were designed to test for direct and indirect market effects on individual emissions and violations, but the subjects were placed in a more neutral environment. Consistent with other emissions trading studies (e.g., Franciosi et al. 1999), we framed the experiments as a production decision in which permits conveyed a license to produce, rather than an emissions decision, to avoid introducing potential biases due to individual attitudes about pollution or emissions trading. During each period of the experiment, subjects simultaneously chose to produce units of a fictitious good and traded in a market for permits that conveyed the right to produce the good. ${ }^{5}$ Participants could produce as many units of the good as they wished (up to a capacity constraint) regardless of the number of permits that they owned. However, at the end of the period, each individual was audited with a known probability. If an individual was audited and found to be non-compliant (i.e., total production exceeded permit holdings), then a penalty was applied. The treatment variables in this paper are the probability of audit, the marginal penalty function, the initial permit allocation, and the total supply of permits. Table 2 summarizes the experimental design. Each cell was repeated three times. The columns represent

\footnotetext{
5 Throughout the paper, we assume a constant relationship between production and emissions, and use these two terms interchangeably. Note that our results are applicable to any market-based program in which tradable permits convey the right to engage in an economic activity.
} 
the different aggregate standards and initial permit allocations, while the three rows reflect the different enforcement strategies (marginal expect penalties or MEP).

Subjects received a benefit from their choice of production, $q$, according to an "Earnings from Production" schedule. The Earnings from Production schedule is a discrete approximation to a linear marginal benefit function $b^{\prime}(q)=\alpha-\beta q$, where $\alpha$ and $\beta$ are positive constants. If $q$ is interpreted as emissions, then $b^{\prime}(q)$ is a standard marginal abatement cost function. Each experiment had eight subjects divided evenly into two firm types. Type-A firms had higher production benefits (higher marginal abatement costs) with parameters $\alpha_{A}=17$ and $\beta_{A}=1$. These firms could produce up to 17 units. The Type-B firms had a lower production benefits (lower marginal abatement costs) with parameters $\alpha_{B}=16$ and $\beta_{B}=2$, and they could produce up to 8 units. $^{6}$

To be compliant, subjects were required to possess sufficient permits, $l$, to cover their production choices. Limiting the total number of permits imposed a cap on aggregate production. We chose two aggregate standards, one high $\left(Q_{H}=56\right)$ and the other low $\left(Q_{L}=28\right)$. In the low aggregate standard experiments, each of the four Type-A firms was allocated three permits, and the four Type-B firms were each given four permits. We call this the (nearly) uniform initial allocation. In the high aggregate standard experiments, there were two different initial allocations of permits. With a uniform initial allocation, each of the eight subjects in an experiment started with seven permits. With a non-uniform initial allocation, the Type-A firms began with 13 permits, and the Type-B firms had a single permit. In the competitive

\footnotetext{
6 This means that for the Type-A firms, the marginal benefit of the first unit was $E \$ 17$ and decreased by $E \$ 1$ per unit for 17 units (i.e., 17, 16, .., 1). For the Type-B firms, the marginal benefit of the first unit was E\$16 and decreased by $\mathrm{E} \$ 2$ per unit for 8 units (i.e., $16,14, \ldots, 2)$.
} 
equilibrium, the Type-B firms would be the net sellers of permits with the uniform initial allocation, and net buyers of permits when the initial allocation is non-uniform.

To check for compliance, each subject's record was examined with a known probability $\pi$. If a subject was audited and found to be non-compliant, that is $q>l$, she was penalized according to a penalty schedule generated from the quadratic function, $f=F(q-l)+(\phi / 2)(q-l)^{2}$, where $F$ and $\phi$ are positive constants. Note that the penalty function is strictly convex, so that each additional unit of violation brings a higher penalty. By changing the parameters of the marginal expected penalty function, $\pi f^{\prime}=\pi[F+\phi(q-l)]$, we developed three enforcement strategies which we labeled $\operatorname{Med}\left(\pi_{H}\right), \operatorname{Med}\left(\pi_{L}\right)$, and Low (the tag Med should be read "medium"). The treatments $\operatorname{Med}\left(\pi_{H}\right)$ and $\operatorname{Med}\left(\pi_{L}\right)$ involve the same marginal expected penalties, but $\operatorname{Med}\left(\pi_{H}\right)$ has a higher monitoring probability $\left(\pi_{H}=0.70\right)$ and a relatively low marginal penalty function, whereas $\operatorname{Med}\left(\pi_{L}\right)$ has a lower monitoring probability $\left(\pi_{L}=0.35\right)$ and a higher marginal penalty function. ${ }^{7}$ Our intention here was to examine whether the subjects reacted differently to monitoring and penalties. Subjects were expected to choose to be noncompliant in these medium MEP treatments. The Low marginal expected penalty function was constructed to be a weaker enforcement strategy, with the low monitoring probability, $\pi_{L}$, and a low marginal penalty function. Enforcement parameter values were chosen, in part, so that the expected marginal penalty functions are parallel to each other-each has a slope of about one.

7 The subjects were given penalty schedules that were discrete approximations to the marginal penalty function $f^{\prime}=F+\phi(q-l)$. The parameters of the penalty schedule $(F, \phi)$ for each marginal expected penalty treatment are $(F=6, \phi=1.43)$ for $\operatorname{Med}\left(\pi_{H}\right),(12,2.90)$ for $\operatorname{Med}\left(\pi_{L}\right)$, and $(2,2.90)$ for Low. The schedule was the same for each firm type with the exception that, since Type-B firms could only produce a maximum of eight units, only the first eight steps were displayed for these firms. 


\subsection{Experiment procedures}

Participants were recruited from the student population at the University of Massachusetts, Amherst. Subjects were paid $\$ 7$ for agreeing to participate and showing up on time, and were then given an opportunity to earn additional money in the experiment. These additional earnings ranged between $\$ 7$ and $\$ 18$, with a mean of $\$ 14.33(\sigma=1.32)$. Earnings were paid in cash at the end of each experiment. Each experiment lasted about 2 hours.

The experiments were run in a computer lab using software designed in Visual Basic specifically for this research. To familiarize subjects with the experiments, we ran a series of training experiments. In the first stage of the trainers, students read online instructions that included interactive questions to ensure that they understood the instructions before proceeding. After everyone had completed the instructions and all questions were answered, the training experiment began. These practice rounds contained all the same features as the "real data" experiments with the exception that we used a different set of parameters. The data from the trainers were discarded.

For the real data sessions, we recruited participants from the pool of trained subjects. Subjects were allowed to participate in multiple sessions. A total of 153 subjects participated in 27 eight-person experiments. Prior to the start of the real data experiments, subjects were given a summary of the experiment instructions (see Appendix). The experimenter read these instructions aloud and answered any questions. Each subject was given a calculator, a pencil and paper. Each experiment consisted of 12 identical five-minute rounds. At the start of each period, the eight subjects were each given an initial allocation of permits and E $\$ 10$ in cash. ${ }^{8}$

8 This extra cash was provided to guard against bankruptcy. During the experiment, subjects earned experimental dollars (E\$) that were converted to US dollars at a pre-announced exchange rate. 
A unique feature of our experiments is that the production decisions and permit market trading were unbundled into two separate, but simultaneous, activities. We did this to allow for the possibility that the production level and permit holdings could differ, thereby introducing a compliance decision. Previous permit market experiments assumed perfect compliance (i.e., production exactly equals the number of permits owned at the end of the trading period) and subjects earned income based on their final permit holdings plus any net income from permit market trading [e.g., Cason et al. (1999), Franciosi et al. (1999)].

Each unit of the good was produced sequentially by clicking on a button that initiated the production process. Production of a single unit took 10 seconds. After production of the unit was completed the "Earnings from Production" were immediately added to the individual's cash balance. During the period and concurrent with the production decision, subjects also had the ability to alter their permit holdings by trading in a continuous double auction. In the auction, individuals could submit bids to buy or asks to sell a single permit. The highest bid and lowest ask price were displayed on the screen. A trade occurred whenever a buyer accepted the current ask or a seller accepted the current bid. After each trade, the current bid and ask were cleared and the market opened for a new set of bids and asks. The trading price history was displayed on the screen.

Each period lasted a total of five minutes. The permit market was open for the entire period, but production had to be completed in four minutes. The four-minute production time was more than sufficient for a subject to produce up to his or her capacity constraint. We provided the additional minute of permit trading after production was completed to give subjects a final opportunity to adjust their permit holdings. The computer screen displayed the time remaining for both production and the permit market. As soon as a period ended, random audits were 
conducted and penalties were assessed. All information relating to audit outcomes were private and not shared with the others in the experiment.

\section{Results}

We will begin our analysis of the results of our experiments with a discussion of general patterns in the permit price, and individual violations and emissions decisions. ${ }^{9}$ We use some of these patterns to motivate our econometric model specifications when estimating these variables. In order to test our hypotheses about the linkages among firms in a permit market via the permit price, we first estimate the permit price and test whether the data support our comparative static predictions. Because our theoretical development and hypotheses suggest that an individual firm's emission and violation decisions are conditioned on the permit price, we then use the estimated permit price as an instrumental variable when estimating these choices. Because these are multi-round experiments, we control for repeated measures using linear mixed effects models. We omit the data from the first period to minimize the effects of learning; this omission does not have a qualitative effect on any of our conclusions.

\subsection{General patterns}

Table 3 presents some summary statistics of permit prices. Note that the average price in each treatment tends to be higher than the competitive equilibrium prediction. Only in treatment $\mathrm{F}$ is the average price statistically indistinguishable from the competitive equilibrium price. Although the average price levels are a bit high, they move as expected: they are higher when the supply of permits is reduced, and when the marginal expected penalty is increased from low to medium.

9 We remind the reader that the experiments were framed as a production, rather than an emissions, decision to avoid introducing any biases. In this section, we will refer to an emissions decision since that was the initial motivation for the research. 
This latter result is consistent with Hypothesis 1, and suggests that enforcement could have an indirect price effect on individual behavior. Note however that with the high standard, average prices are higher when the initial allocation of permits is not uniform. Thus, our theoretical expectation that the initial allocation of permits should have no impact on individual choices and market outcomes (Hypothesis 4) appears to be in doubt.

Tables 4 and 5 present some summary statistics for individual violations and emissions. Rather than discuss all the relationships that are apparent in these data, we would like to leave that for the econometric analyses. However, an interesting pattern emerges from these summary statistics that plays an important role in how we analyze and interpret individual choices of emissions and compliance. Stranlund and Dhanda (1999) showed that holding monitoring, enforcement and the permit price constant, a change in any parameter that affects the abatement costs of a firm has no effect on its choice of violation; thus, $v_{\alpha}^{i}=0$ as noted in Table 1 . In the competitive equilibrium, this implies that violations should be identical across firm type.

However, Table 4 shows that for each treatment the mean violations of the firm types are clearly different, but whether Type-A firms tend toward higher or lower violations than Type-B firms depends on the initial allocation of permits. In particular, consider first the uniform allocation treatments (A, B, C, D, E, and F in Table 3). The Type-A firms are predicted to be the net buyers of permits in these treatments. Clearly they tend toward higher violations than the Type-B firms in these treatments. For the non-uniform allocation treatments (G, H, and I), the Type-B firms are predicted to be the permit buyers, and they are the ones that tend toward higher violations. It appears, therefore, that the differences in violations by firm type do not have as much to do with difference in their marginal abatements costs, but rather whether the initial allocation of permits 
makes them net buyers or sellers of permits. Of course, this speculation is easily tested and we will do so shortly.

As with violations, mean emissions also show a consistent pattern. In Table 5, note that with a uniform allocation, when the Type-A firms are predicted to be net buyers of permits, their emissions are significantly lower than the competitive equilibrium prediction. On the other hand, for the three non-uniform allocation treatments in which Type-A firms are predicted to be net sellers of permits, their emissions are slightly higher than predicted, although in all three cases this difference is not statistically significant. The opposite is true for Type-B firms. In the treatments involving a uniform allocation of permits, the Type-B firms are predicted to be net sellers of permits, and their average emissions are consistently greater than the competitive equilibrium. This does not hold when they are predicted to be net buyers of permits in the nonuniform allocation treatments. Their average emissions in treatments $\mathrm{G}$ and I are less than the competitive equilibrium prediction; in treatment $\mathrm{H}$ there is no statistical difference between their average emissions and the equilibrium prediction.

Thus, it appears that net sellers of permits tend toward higher emissions and lower violations. This implies that net sellers of permits are also inclined to retain more permits than predicted. Consequently, fewer permits change hands than predicted, which is consistent with our observation that average permit prices are higher than the competitive equilibrium predictions.

\subsection{Regression results and tests of hypotheses}

Table 6 presents the results of a linear mixed effects model of the permit price that controls for the repeated measures. The dependent variable is the price of each trade in period $t=2, \ldots, 12$ of 
group $j=1, \ldots, 27$. The marginal expected penalty (low vs. medium MEP), the aggregate standard (low vs. high standard), and the initial allocation (uniform vs. non-uniform) are modeled as fixed effects. Note that we have combined the two medium marginal expected penalties. Assuming risk-neutral subjects, since both $\operatorname{Med}\left(\pi_{H}\right)$ and $\operatorname{Med}\left(\pi_{L}\right)$ have the same marginal expected penalties, in theory both should lead to identical market outcomes. We tested a model of price with separate dummy variables for the two medium MEP treatments. An F-test of the null hypothesis that the coefficients on the dummy variables for the $\operatorname{Med}\left(\pi_{H}\right)$ and $\operatorname{Med}\left(\pi_{L}\right)$ treatments are equal cannot be rejected at any conventional level of significance $(\mathrm{F}=1.55$, $\mathrm{p}=0.21)$. We conducted the same exercise for individual emissions and violation decisions and found the same result. Thus, decreasing monitoring and increasing penalties, but leaving the marginal expected penalty function unchanged had no affect on individual decisions and market outcomes.

The regression results in Table 6 confirm the impressions we reached by simply comparing average prices across treatment. The coefficient on MediumMEP indicates that, consistent with Hypothesis 1, increased enforcement due to either a higher penalty or a higher monitoring probability will put upward pressure on the equilibrium price. In a moment we will show that this shift in price will have an indirect effect on individual emissions and violations. The NonUniform coefficient is positive and weakly significant, which contradicts Hypothesis 4 as we expected from our perusal of the average price results. Lastly, the coefficient on HighStandard is strongly negative and significant, indicating the unsurprising result that permit prices fall with a greater supply of permits.

Table 7 presents the results of a linear mixed effects model for individual violations. Using an instrumental variable approach, PriceHat is the estimated price from the model in Table 6. 
Since the impact of the non-uniform allocation clearly differs by firm type, depending upon whether the firm is predicted to be a net seller or buyer of permits, we capture this effect with the variable NetSeller, which is a fixed effect that equals one if the firm is predicted to be a net seller (Type-A firms for the non-uniform allocations and Type-B firms for the uniform allocations); FirmTypeA is a fixed effect that equals one for Type-A firms.

From Table 7, note the positive and significant impact of price, and the negative and significant impact of enforcement. Consistent with Hypothesis 2, increased enforcement has a negative effect on individual violations as well as a countervailing positive impact through the permit price. From the price equation in Table 6 , an increase in enforcement induces a $\$ 2.56$ increase in price. Combining this with the PriceHat coefficient of 0.12 in Table 7 yields a positive price effect of enforcement on individual violations of +0.31 . The coefficient on MediumMEP in Table 7 indicates a negative direct effect on violations of -1.69 . The total effect of increasing enforcement is, therefore, -1.38 . As predicted, the productivity of enforcement in reducing violations is partially offset by the resulting increase in permit prices. In this case, the price effect reduces the direct effect of enforcement by $18 \%$.

Our estimate of the equilibrium effect of increased enforcement on individual violations is only a bit smaller than the competitive equilibrium effect, but the component effects are not very close. In the competitive equilibrium, the direct effect of enforcement on violations is -3.60 and the price effect is +2.10 . Compare these to our estimated effects of -1.70 and +0.31 , respectively. The total effect is -1.50 , which is only slightly higher than the -1.39 estimated effect. Although our estimates of the individual effects deviate substantially from the competitive equilibrium effects, the estimated total effect is reasonably accurate. More interesting is the difference in the strength of the indirect price effect. The competitive equilibrium prediction is that the indirect 
price effect of enforcement reduces the direct effect by about $58 \%$, while our estimate of this value is only $18 \%$.

Recall that in comparing average violations across treatments that we suggested that differences in violations by firm type may have had more to do with whether they were net buyers or sellers of permits than with difference in their marginal abatements costs. This is confirmed by the regressions results. Note that the coefficient on FirmTypeA is small and insignificant, whereas the NetSeller coefficient is negative and significant. Thus, the only distinction in firms that drives difference in their individual violations appears to be whether they are net sellers of permits or net buyers, not differences in marginal abatement costs. Indeed, as we suspected, those that are predicted to be net sellers have significantly lower violation levels than those that are predicted to be net buyers.

We designed our experiments to focus on imperfect compliance so that the competitive equilibrium for each of the treatments involves positive violations by all firms. In our data, however, subjects were compliant in $27 \%$ of the observations. Because of this, we estimated the binary noncompliance decision with a random effects logit model $(1=$ noncompliant $)$. The results in Table 8 are consistent with those in Table 7. The PriceHat, NetSeller and MediumMEP coefficients have the same signs and remain highly significant, while the FirmTypeA coefficient becomes weakly significant $(\mathrm{p}=0.075)$. Note the negative direct effect of increased enforcement and the positive price effect on an individual's choice of whether to be noncompliant. As with the decision about the level of violation, we are led to decompose the total effect of enforcement on the noncompliance decision into direct and indirect price effects.

We decomposed the noncompliance decision by first calculating the probability of noncompliance given a change in MEP from low to medium, but holding price constant at the 
low MEP price. This yields the direct effect of a change in enforcement. Subtracting this effect from the total change in the estimated probability of noncompliance yields the indirect price effect. For example, consider the probability of noncompliance when MEP increases from low to medium for a Type-A firm with a uniform permit allocation and a high standard (from treatment $\mathrm{F}$ to $\mathrm{D}+\mathrm{E}$ ). The estimated probability of noncompliance is 0.99 with the low MEP, which decreases (as one would expect) to 0.69 when the MEP is increased to medium. Thus, the total effect of increasing enforcement is to reduce the probability of noncompliance by 0.30 . However, holding the permit price constant at the estimated low MEP price (\$4.22), we see that the direct effect of increased enforcement reduces the probability to 0.48 . Therefore, the -0.30 total effect of increased enforcement is decomposed into a direct effect of $-0.51(=0.48-0.99)$ and a countervailing price effect of $+0.21(=0.69-0.48)$. The price effect of enforcement offsets the direct effect by $42 \%$.

There are six combinations of firm type, aggregate standard and initial allocation for which we can calculate these effects. The ratios of the price effects to the direct effects range from -30 to $-54 \%$ (mean $-43 \%$ ). As with our analysis of the direct and indirect effects of enforcement on the levels of individual violations, the enforcement-induced price effect significantly dampens the productivity of increased enforcement on compliance decisions.

Let us now turn to the analysis of individual emissions decisions. Recall that our third hypothesis about the direct and indirect effects of enforcement is that a change in enforcement has no direct effect on emissions, only a negative price effect. Table 9 presents the results of linear mixed effects models for individual emissions. Consistent with Hypotheses 3, the permit price has a negative and significant effect on emissions, while the effect of the marginal expected penalty is small and insignificant. Thus, as predicted, the only impact of increased enforcement 
on emissions is through its effect on permit prices. Recall from the price results in Table 6 that increasing the marginal expected penalty from low to medium leads to an increase in the permit price of $\$ 2.56$. Multiplying this by the coefficient on PriceHat in the emissions equation yields -1.29 as the total effect of increasing enforcement on individual emissions. This is only a bit smaller than the predicted effect of -1.575 .

As with individual violations, the significant positive coefficient on the NetSeller variable is consistent with our suspicion that those who are predicted to be net sellers of permits tend to emit more than those who are predicted to be net buyers of permits. Lastly, note that the strongly positive coefficient on FirmTypeA is consistent with the prediction that those with higher abatement costs will tend to emit more (recall $q_{\alpha}^{i}>0$ from Table 1).

\section{Conclusion}

Enforcement of emissions trading programs is different from enforcing emissions taxes and standards in a very fundamental way. Since firms in an emissions trading program are linked together through the permit market, so too are their compliance choices. This implies that enforcement strategies for trading programs must account for the direct effects of enforcement on compliance and emissions decisions, as well as indirect effects that occur because changes in enforcement can induce changes in permit prices. Obviously, these indirect market effects are not present when firms face fixed emissions standards or taxes.

The results of our laboratory experiments generally support the conclusions of a theoretical model of compliance behavior in emissions trading programs. The productivity of increased enforcement pressure to reduce noncompliance is partially offset by a countervailing

price effect. Our estimate of the size of this offset is smaller than predicted, but nevertheless its magnitude is such that it cannot be ignored. Moreover, our analysis of the binary choice of 
whether to be compliant indicates that the price effect has a large impact on a firm's compliance decision. Regulators who ignore this indirect price effect could significantly over-estimate the effectiveness of any attempt to reduce violations in an emissions trading program.

Furthermore, there is no direct effect of enforcement on individual emissions choices, only a price effect. One might reasonably expect that increased enforcement would lead to lower emissions, which we find to be true, but this occurs only if increased enforcement induces higher permit prices. Unless an increase in enforcement pressure is sufficient to affect the market price, it will have no impact on individual emission choices. Regulators should be aware that modest increases in enforcement pressure might have little or no impact on emissions levels and environmental quality.

All of our hypotheses have been confirmed by our experimental results, except one. Contrary to theoretical predictions, the initial allocation of permits has a significant impact on individual choices of violations and emissions, as well as on permit prices. Those who were predicted to be net sellers of permits tended to have higher emissions and lower violations than those who were predicted to be net buyers of permits. The effect of the initial allocation of permits on emissions choices could have significant implications for the cost-effectiveness of emissions trading programs. Furthermore, the effect on violations could have significant implications for enforcing these programs. We believe that the effects of the initial allocation of permits deserve further study, and suggest that future work in this area focus more closely on this issue.

In general it is clear that if emissions trading programs are to fulfill their theoretical promise of cost-effective pollution control, they must be enforced well. Designing appropriate enforcement strategies requires a comprehensive understanding of compliance behavior in these 
programs. The theory of compliance and enforcement of emissions trading programs is well advanced, but there are virtually no empirical analyses of the results of this literature. Further experimental analyses, like that contained in this paper, would help develop a more theoretically and empirically balanced understanding of compliance behavior in emissions trading programs. 


\section{References}

Alm, J., B. R.Jackson, and M. McKee. 1992a. "Estimating the Determinants of Taxpayer Compliance with Experimental Data." National Tax Journal 45:107-114.

Alm, J., B. R.Jackson, and M. McKee. 1992b. “Institutional Uncertainty and Taxpayer Compliance." American Economic Review 82:1018-1026.

Alm, J. 1998. "Tax Compliance and Administration.” Working paper, Department of Economics. University of Colorado.

Cason, T.N. 1995. "An Experimental Investigation of the Seller Incentives in the EPA's Emissions trading Auction." American Economic Review 85(4):905-922.

Cason, T.N. and L. Gangadharan. 2004. "Emissions Variability in Tradable Permit Markets with Imperfect Enforcement and Banking." Working paper, Department of Economics, Purdue University.

Cason, T.N., and C.R. Plott. 1996. "EPA's New Emissions Trading Mechanism: A Laboratory Evaluation." Journal of Environmental Economics and Management 30(2):133-160.

Cason, T.N. S.R. Elliott, and M.R. Van Boening. 1999. "Speculation in Experimental Markets for Emissions Permits." In Emissions Permit Experiments. Research in Experimental Economics, vol. 7. Edited by R.M. Isaac and C. Holt. Stamford, CT: JAI Press.

Chavez, C. A. and J. K. Stranlund. 2003. "Enforcing Transferable Permit Systems in the Presence of Market Power." Environmental and Resource Economics 25 (1), 65-78, May.

Chavez, C. A. and J. K. Stranlund. 2004. "Enforcing Transferable Permit Systems in the Presence of Transaction Costs." Working Paper No. 2004-3, Department of Resource Economics, University of Massachusetts, Amherst.

Franciosi, R., R.M. Isaac, and S.S. Reynolds. 1999. "Experimental Research on the EPA's "TwoTier" System for Marketable Emissions Permits." In Emissions Permit Experiments. Research in Experimental Economics, vol. 7. Edited by R.M. Isaac and C. Holt. Stamford, CT: JAI Press, pp. 25-44.

Hahn, R. 1984. "Market Power and Transferable Property Rights.” Quarterly Journal of Economics, 99, 735-765.

Harford, J. 1978. "Firm Behavior Under Imperfectly Enforceable Pollution Standards and Taxes." Journal of Environmental Economics and Management 5: 26-43.

Isaac, R.M. and C. Holt. 1999. Research in Experimental Economics: Emissions Permit Experiments. Vol. 7. Stamford, CT: JAI Press, Inc.

Ishikida, T., J. Ledyard, D. Porter, and M. Olson. 1998. "Implementation of a Combinatorial Market. The Experiments Behind the Automated-Environmental Credit Exchange (ACE)." Working paper. California Institute of Technology. Pasadena, CA.

Keeler, A. 1991. "Noncompliant Firms in Transferable Discharge Permit Markets: Some Extensions." Journal of Environmental Economics and Management 21: 180-189.

Malik, A. S. 2002. "Further Results on Permit Markets with Market Power and Cheating." Journal of Environmental Economics and Management 44(3), 371-90. 
Malik, A. S. 1992. "Enforcement Cost and the Choice of Policy Instruments for Controlling Pollution." Economic Inquiry 30: 714-721.

Malik, A. S. 1990. "Markets for Pollution Control when Firms are Noncompliant." Journal of Environmental Economics and Management 18: 97-106.

Montgomery, W. D. 1972. "Markets in Licenses and Efficient Pollution Control Programs." Journal of Economic Theory 5(3): 395-418.

Stavins, R. 1995. “Transaction Costs and Tradeable Permits,” Journal of Environmental Economic and Management 29, 133-148.

Stranlund, J. K. and K. Kanwalroop. 1999. "Endogenous Monitoring and Enforcement of a Transferable Emissions Permit System." Journal of Environmental Economics and Management 38(3): 267-282.

Stranlund, J.K. and C.A. Chavez. 2000. "Effective Enforcement of a Transferable Emissions Permit System with a Self-Reporting Requirement." Journal of Regulatory Economics 18(2), 113-131.

van Egteren, H. and M. Weber. 1996. "Marketable Permits, Market Power, and Cheating." Journal of Environmental Economics and Management 30: 161-173. 
Table 1. Comparative statics of an individual firm's choices

\begin{tabular}{|c|c|c|c|c|}
\hline \multirow{6}{*}{ 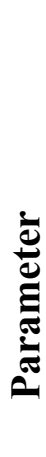 } & & \multicolumn{3}{|c|}{ Choice } \\
\hline & & $\operatorname{Emissions}\left(\mathbf{q}^{i}\right)$ & Permits $\left(1^{\mathrm{i}}\right)$ & Violations $\left(v^{i}\right)$ \\
\hline & $\pi$ & $q_{\pi}^{i}=0$ & $l_{\pi}^{i}>0$ & $v_{\pi}^{i}<0$ \\
\hline & $\phi$ & $q_{\phi}^{i}=0$ & $l_{\phi}^{i}>0$ & $v_{\phi}^{i}<0$ \\
\hline & $p$ & $q_{p}^{i}<0$ & $l_{p}^{i}<0$ & $v_{p}^{i}>0$ \\
\hline & $\alpha^{i}$ & $q_{\alpha}^{i}>0$ & $l_{\alpha}^{i}>0$ & $v_{\alpha}^{i}=0$ \\
\hline
\end{tabular}

Table 2. Experimental design

\begin{tabular}{cccc}
\hline & \multicolumn{3}{c}{ Aggregate Standard } \\
\cline { 2 - 4 } & Uniform Allocation & $\begin{array}{c}\text { Non-uniform } \\
\text { Allocation }\end{array}$ \\
\cline { 2 - 4 } $\begin{array}{c}\text { Enforcement } \\
\text { Strategy }\end{array}$ & $\begin{array}{c}\text { Low } \\
\text { Standard }\end{array}$ & $\begin{array}{c}\text { High } \\
\text { Standard }\end{array}$ & $\begin{array}{c}\text { High } \\
\text { Standard }\end{array}$ \\
\hline $\operatorname{Med}\left(\pi_{H}\right) M E P$ & $\mathrm{~A}$ & $\mathrm{D}$ & $\mathrm{G}$ \\
$\operatorname{Med}\left(\pi_{L}\right) M E P$ & $\mathrm{~B}$ & $\mathrm{E}$ & $\mathrm{H}$ \\
$\operatorname{Low} M E P$ & $\mathrm{C}$ & $\mathrm{F}$ & $\mathrm{I}$ \\
\hline
\end{tabular}


Table 3. Permit Price Summary Statistics

\begin{tabular}{|c|c|c|c|c|c|c|}
\hline \multirow{4}{*}{ 胥 } & $\begin{array}{l}\text { Enforcement } \\
\text { Strategy }\end{array}$ & $\begin{array}{l}\text { Competitive } \\
\text { Equilibrium }\end{array}$ & Mean & Median & $\begin{array}{l}\text { Standard } \\
\text { Deviation }\end{array}$ & $\begin{array}{l}\text { 95\% Confidence } \\
\text { Interval }\end{array}$ \\
\hline & A. $\operatorname{Med}\left(\pi_{H}\right) M E P$ & \multirow{2}{*}{$8-8.20$} & 9.61 & 9.30 & 1.18 & $9.48-9.75$ \\
\hline & B. $\operatorname{Med}\left(\pi_{L}\right) M E P$ & & 13.26 & 13.50 & 1.84 & $13.08-13.44$ \\
\hline & C. Low MEP & 6 & 8.11 & 7.90 & 1.55 & $7.94-8.29$ \\
\hline \multirow{6}{*}{ 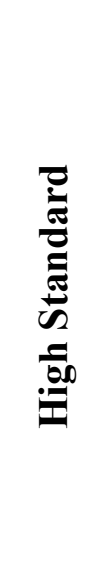 } & D. $\operatorname{Med}\left(\pi_{H}\right) M E P$ & \multirow{4}{*}{$6-6.20$} & 7.09 & 7.25 & 1.02 & $6.99-7.20$ \\
\hline & $\begin{array}{l}\text { G. } \operatorname{Med}\left(\pi_{H}\right) M E P \\
\text { non-uniform }\end{array}$ & & 7.79 & 7.60 & 1.10 & $7.68-7.89$ \\
\hline & E. $\operatorname{Med}\left(\pi_{L}\right) M E P$ & & 6.74 & 6.85 & 0.58 & $6.68-6.81$ \\
\hline & $\begin{array}{l}\text { H. } \operatorname{Med}\left(\pi_{L}\right) M E P \\
\text { non-uniform }\end{array}$ & & 7.24 & 7.20 & 1.39 & $7.11-7.37$ \\
\hline & F. Low MEP & \multirow[b]{2}{*}{4} & 3.97 & 4.00 & 0.74 & $3.87-4.06$ \\
\hline & $\begin{array}{l}\text { I. Low MEP } \\
\text { non-uniform }\end{array}$ & & 6.50 & 7.00 & 1.36 & $6.34-6.67$ \\
\hline
\end{tabular}


Table 4. Summary Statistics for Individual Violations

\begin{tabular}{|c|c|c|c|c|c|c|c|}
\hline & $\begin{array}{l}\text { Enforcement } \\
\text { Strategy }\end{array}$ & $\begin{array}{l}\text { Competitive } \\
\text { Equilibrium }\end{array}$ & $\begin{array}{l}\text { Firm } \\
\text { Type }\end{array}$ & Mean & Median & $\begin{array}{l}\text { Standard } \\
\text { Deviation }\end{array}$ & $\begin{array}{l}\text { 95\% Confidence } \\
\text { Interval }\end{array}$ \\
\hline \multirow{6}{*}{ 总 } & \multirow{2}{*}{ A. $\operatorname{Med}\left(\pi_{H}\right) M E P$} & \multirow{4}{*}{3} & $\mathrm{~A}$ & 3.05 & 3.00 & 0.98 & $2.88-3.22$ \\
\hline & & & $\mathrm{B}$ & 1.98 & 2.00 & 1.45 & $1.73-2.23$ \\
\hline & \multirow{2}{*}{ B. $\operatorname{Med}\left(\pi_{L}\right) M E P$} & & A & 1.86 & 1.00 & 1.99 & $1.51-2.20$ \\
\hline & & & B & 1.20 & 1.00 & 1.4 & $0.96-1.44$ \\
\hline & \multirow{2}{*}{ C. Low MEP } & \multirow{2}{*}{$(4$ or 5$)$} & A & 3.66 & 3.00 & 1.95 & $3.32-4.00$ \\
\hline & & & $\mathrm{B}$ & 3.26 & 3.00 & 1.54 & $2.99-3.52$ \\
\hline \multirow{12}{*}{ 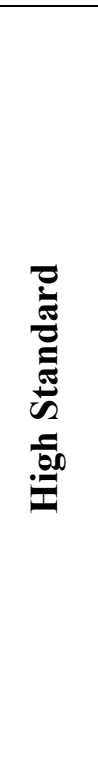 } & \multirow{2}{*}{ D. $\operatorname{Med}\left(\pi_{H}\right) M E P$} & \multirow{8}{*}{1} & $\mathrm{~A}$ & 1.17 & 1.00 & 1.1 & $0.98-1.36$ \\
\hline & & & $\mathrm{B}$ & 0.73 & 0.00 & 1.3 & $0.50-0.95$ \\
\hline & \multirow{2}{*}{$\begin{array}{l}\text { G. } \operatorname{Med}\left(\pi_{H}\right) M E P \\
\text { non-uniform }\end{array}$} & & $\mathrm{A}$ & 0.63 & 0.00 & 1.24 & $0.42-0.84$ \\
\hline & & & $\mathrm{B}$ & 1.35 & 1.00 & 1.2 & $1.14-1.55$ \\
\hline & \multirow{2}{*}{ E. $\operatorname{Med}\left(\pi_{L}\right) M E P$} & & A & 1.42 & 1.00 & 1.34 & $1.19-1.66$ \\
\hline & & & B & 0.80 & 0.00 & 1.46 & $0.54-1.05$ \\
\hline & \multirow{2}{*}{$\begin{array}{l}\text { H. } \operatorname{Med}\left(\pi_{L}\right) M E P \\
\text { non-uniform }\end{array}$} & & $\mathrm{A}$ & 0.77 & 0.00 & 2.26 & $0.38-1.15$ \\
\hline & & & B & 1.48 & 1.00 & 1.71 & $1.18-1.77$ \\
\hline & \multirow{2}{*}{ F. Low MEP } & \multirow{4}{*}{$(2$ or 3$)$} & A & 3.61 & 3.00 & 2.38 & $3.20-4.02$ \\
\hline & & & $\mathrm{B}$ & 1.41 & 1.00 & 1.31 & $1.18-1.63$ \\
\hline & \multirow{2}{*}{$\begin{array}{l}\text { I. Low MEP } \\
\text { non-uniform }\end{array}$} & & A & 1.76 & 1.00 & 2 & $1.41-2.10$ \\
\hline & & & $\mathrm{B}$ & 2.81 & 2.00 & 2.04 & $2.46-3.16$ \\
\hline
\end{tabular}


Table 5. Summary Statistics for Individual Emissions

\begin{tabular}{|c|c|c|c|c|c|c|c|}
\hline & & $\begin{array}{c}\text { Enforcement } \\
\text { Strategy }\end{array}$ & $\begin{array}{l}\text { Competitive } \\
\text { Equilibrium }\end{array}$ & Mean & Median & $\begin{array}{l}\text { Standard } \\
\text { Deviation }\end{array}$ & $\begin{array}{c}\text { 95\% Confidence } \\
\text { Interval } \\
\end{array}$ \\
\hline \multirow{9}{*}{$\underset{\Xi}{\Xi}$} & \multirow{3}{*}{ } & A. $\operatorname{Med}\left(\pi_{H}\right) M E P$ & \multirow{2}{*}{9} & 7.34 & 7.00 & 1.19 & $7.14-7.55$ \\
\hline & & B. $\operatorname{Med}\left(\pi_{L}\right) \operatorname{MEP}$ & & 5.77 & 5.00 & 2 & $5.43-6.12$ \\
\hline & & C. Low MEP & 11 & 8.33 & 8.00 & 1.69 & $8.04-8.62$ \\
\hline & \multirow{6}{*}{ 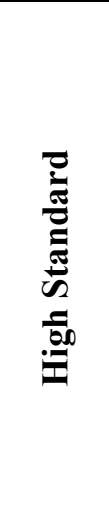 } & D. $\operatorname{Med}\left(\pi_{H}\right) M E P$ & \multirow{4}{*}{11} & 10.37 & 10.00 & 1.09 & $10.18-10.56$ \\
\hline & & $\begin{array}{l}\text { G. } \operatorname{Med}\left(\pi_{H}\right) M E P \\
\text { non-uniform }\end{array}$ & & 11.35 & 10.00 & 2.54 & $10.91-11.79$ \\
\hline & & E. $\operatorname{Med}\left(\pi_{L}\right) M E P$ & & 10.59 & 11.00 & 1.28 & $10.37-10.81$ \\
\hline & & $\begin{array}{l}\text { H. } \operatorname{Med}\left(\pi_{L}\right) M E P \\
\text { non-uniform }\end{array}$ & & 11.15 & 11.00 & 1.42 & $10.91-11.40$ \\
\hline & & F. Low MEP & \multirow[b]{2}{*}{13} & 11.84 & 12.00 & 1.71 & $11.55-12.14$ \\
\hline & & $\begin{array}{l}\text { I. Low MEP } \\
\text { non-uniform }\end{array}$ & & 13.12 & 13.00 & 1.53 & $12.86-13.39$ \\
\hline \multirow{9}{*}{$\stackrel{\oplus}{\Xi}$} & \multirow{3}{*}{ 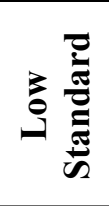 } & A. $\operatorname{Med}\left(\pi_{H}\right) M E P$ & \multirow{2}{*}{4} & 4.69 & 5.00 & 0.96 & $4.52-4.85$ \\
\hline & & B. $\operatorname{Med}\left(\pi_{L}\right) M E P$ & & 4.28 & 4.00 & 1.29 & $4.06-4.50$ \\
\hline & & C. Low MEP & 5 & 5.58 & 6.00 & 0.72 & $5.46-5.71$ \\
\hline & \multirow{6}{*}{ 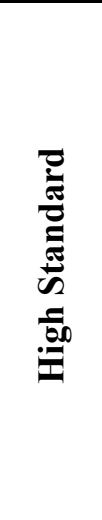 } & D. $\operatorname{Med}\left(\pi_{H}\right) M E P$ & \multirow{4}{*}{5} & 5.53 & 5.00 & 0.96 & $5.36-5.70$ \\
\hline & & $\begin{array}{l}\text { G. } \operatorname{Med}\left(\pi_{H}\right) M E P \\
\text { non-uniform }\end{array}$ & & 4.63 & 5.00 & 0.74 & $4.50-4.76$ \\
\hline & & E. $\operatorname{Med}\left(\pi_{L}\right) M E P$ & & 5.63 & 5.00 & 0.88 & $5.48-5.78$ \\
\hline & & $\begin{array}{l}\text { H. } \operatorname{Med}\left(\pi_{L}\right) M E P \\
\text { non-uniform }\end{array}$ & & 5.09 & 5.00 & 1.18 & $4.89-5.29$ \\
\hline & & F. Low MEP & \multirow[b]{2}{*}{6} & 7.18 & 7.00 & 0.71 & $7.06-7.30$ \\
\hline & & $\begin{array}{l}\text { I. Low MEP } \\
\text { non-uniform }\end{array}$ & & 5.45 & 5.00 & 1.19 & $5.24-5.65$ \\
\hline
\end{tabular}


Table 6. Random Effects Estimation of Permit Price

\begin{tabular}{ccccc}
\hline Effect & Estimate & Standard Error & t-value & $\operatorname{Pr}>|\mathbf{t}|$ \\
Intercept & 8.2643 & 0.5609 & 14.73 & $<.0001$ \\
MediumMEP & 2.5606 & 0.5321 & 4.81 & $<.0001$ \\
NonUniform & 1.1059 & 0.6142 & 1.80 & 0.0719 \\
HighStandard & -4.0423 & 0.6144 & -6.58 & $<.0001$ \\
3044 observations, 216 subjects. Wald $\chi^{2}(3)=37.55(\mathrm{p}=0.000)$ & \\
\hline
\end{tabular}

Table 7. Random Effects Estimation of Individual Violations

\begin{tabular}{ccccc}
\hline Effect & Estimate & Standard Error & t-value & Pr $>|\mathbf{t}|$ \\
Intercept & 2.454 & 0.337 & 7.28 & 0.000 \\
PriceHat & 0.120 & 0.043 & 2.78 & 0.006 \\
MediumMEP & -1.689 & 0.220 & -7.68 & 0.000 \\
NetSeller & -0.866 & 0.190 & -4.55 & 0.000 \\
FirmTypeA & 0.037 & 0.190 & 0.2 & 0.845 \\
\hline
\end{tabular}

2376 observations, 216 subjects. Wald $\chi^{2}(4)=72.70(p=0.000)$ 
Table 8. Random Effects Logit Estimation of the Probability of an Individual Violation $(1$ = violation)

\begin{tabular}{ccccc}
\hline Effect & Estimate & Standard Error & t-value & $\operatorname{Pr}>|\mathbf{t}|$ \\
& & & & \\
Intercept & 3.481 & 0.520 & 6.70 & 0.000 \\
PriceHat & 0.347 & 0.066 & 5.22 & 0.000 \\
MediumMEP & -4.418 & 0.453 & -9.75 & 0.000 \\
NetSeller & -1.233 & 0.284 & -4.35 & 0.000 \\
FirmTypeA & -0.615 & 0.345 & -1.78 & 0.075 \\
2376 observations, 216 subjects. Wald $\chi^{2}(4)=138.45(\mathrm{p}=0.000)$ & \\
\hline
\end{tabular}

Table 9. Random Effects Estimation of Individual Emissions

\begin{tabular}{ccccc}
\hline Effect & Estimate & Standard Error & t-value & Pr $>|\mathbf{t}|$ \\
Intercept & 8.1757 & 0.3420 & 23.90 & $<0.0001$ \\
PriceHat & -0.5053 & 0.0437 & -11.57 & $<0.0001$ \\
MediumMEP & -0.0888 & 0.2231 & -0.40 & 0.6906 \\
NetSeller & 1.6294 & 0.1931 & 8.44 & $<0.0001$ \\
FirmTypeA & 5.1888 & 0.1931 & 26.87 & $<0.0001$ \\
& & & \\
2376 observations, 216 subjects. Wald $\chi^{2}(4)=360.29(\mathrm{p}=0.000)$ & \\
\hline
\end{tabular}




\section{Appendix: Instructions Summary ${ }^{10}$}

Thank you for agreeing to participate in today's experiment. You have all seen a version of this experiment before. Before we begin, I would like to review the instructions for today's experiment.

It is very important to remember that although the experiment may be similar, some or all of the numbers may have changed. Do NOT assume that any of the information or results from a previous experiment will be useful in helping you to make your decisions today.

The purpose of the experiment is to give you an opportunity to earn as much money as possible. What you earn will depend on your decisions, as well as the decisions of others. As before you can produce as many units as you want regardless of the number of permits you own, but you could face a financial penalty if you do not own a permit for each unit you produce.

- During the period, you can earn money in two ways:

1. Produce units of the fictitious good. For each unit you produce, you will earn a specified amount of money that will be added to your cash balance.

2. Sell permits in the permit market. The selling price you receive for a permit will be added to your cash balance.

- Money will be subtracted from your cash balance if:

1. You choose to buy additional permits. The purchase price you pay will be deducted from your cash balance.

2. You are audited and if the total number of units you produce exceeds the number of permits you own.

\section{Production Highlights}

- Your Earnings from Production table tells you how many units you can produce and how much you will earn from each unit you produce. You might earn a different amount of money for each unit produced.

- Production of each unit takes a specified amount of time

- You can only produce one unit at a time.

\footnotetext{
${ }^{10}$ This instructions summary was given to students and read aloud by the experimenter before each session. During the trainers, subjects read a more detailed set of online instructions. The text of the detailed instructions is available from the authors upon request.
} 
- The Production Timer tells you how much time is left for you to produce more units.

- In order to start production of a unit, there must be sufficient time on the Production Timer to complete production of the unit.

- To start production or to place an order for additional units, click the plus (+) button. If production is idle, then production will begin immediately.

- You can cancel units that have been ordered if production has not yet begun. To do so, click the minus (-) button.

- Earnings from the units produced are automatically added to your cash balance when production is completed.

- The last row of the "Earnings from Production" table tells you the maximum number of units you are able to produce.

- Under the "Earnings from Production" table, you can see the production status of each unit (produced, in production, or planned).

\section{Permit Market Highlights}

- You will be given an opportunity to buy and/or sell permits in the Permit Market.

- There are 4 ways in which you can participate in the market:

1. Make an offer to buy a permit.

a. To do so, enter your price next to the My Buying Price and click Buy.

b. All buying prices must be GREATER than the Current Buying Price.

2. Make an offer to sell a permit.

a. To do so, enter your price next to the My Selling Price and click Sell.

b. All selling prices must be LOWER than the Current Selling Price.

3. Purchase a permit at the Current Selling Price.

a. To do so, enter the Current Selling Price next to My Buying Price

b. or click the Buy button next to the Current Selling Price.

4. Sell a permit at the Current Buying Price.

a. To do so, enter the Current Buying Price next to My Selling Price

b. or click the Sell button next to the Current Buying Price. 
- After each trade is completed, your permit balance will be automatically updated. Your cash balance will automatically be updated to reflect price you paid to buy the permit, or the price you received for selling the permit. This is shown in the My Balances section of your screen.

\section{Auditing Highlights}

- The computer monitor always knows how many permits you own and your cash balance. The computer does not know how many units you actually produced unless you are audited.

- There is an XX\% chance that you will be audited, and (1-XX)\% chance you will not be audited.

- If you are audited, the computer monitor will check to see how many units you actually produced. If the number of units you produced exceeds the number of permits you own, you will receive a financial penalty. The Permit Shortfall Table lists the penalties you will face.

To summarize, your total earnings for the period will be calculated as follows:

Your initial cash balance

+ Earnings from production of the good

+ Selling price for permits you sell in the permit market

- Purchase price for permits you buy in the permit market

- Penalties for a permit shortfall (only if you are audited and if you over produced)

$=$ Total earnings for the period

At the end of the experiment, we will add up your total earnings for each period and you will be paid in cash for these earnings. Please raise your hand if you have any questions. 